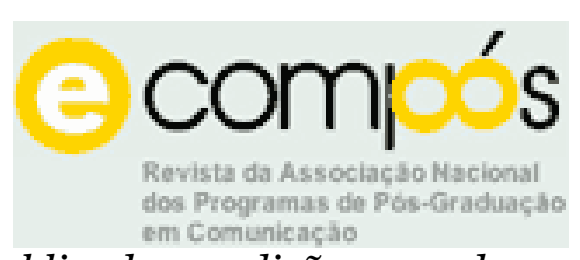

Este artigo foi publicado na edição 1, em dezembro de 2004, da revista eletrônica e-compós: http://www.compos.org.br/e-compos

\title{
QUANDO E COMO A TV FALA DE SI
}

\author{
Profa $^{a}$. Dra . Elizabeth Bastos Duarte \\ Unisinos
}

\begin{abstract}
Resumo: A televisão não se vexa: cada vez mais substitui o mundo exterior real do qual ela deveria dar conta, por aquele constituído no interior do próprio meio, tornando a si própria tema e objeto de seus programas. A tendência não é nova, mas vem-se difundindo de forma vertiginosa sob diferentes modalidades discursivas e com funções estratégicas diversas. O presente trabalho propõe-se a analisar essas formas de autoconvocação - das mais sutis e subterrâneas àquelas que escracham uma auto-referencialidade ostensiva - em suas diferentes modalidades, configurações e funções, tomando como referência uma amostragem de programas, constantes da grade de programação da Rede Globo de Televisão, em que essa estratégia se manifesta.
\end{abstract}

Palavras-chave: metadiscursividade - autoreflexividade - autopromoção

\section{- Considerações introdutórias}

Um dos fenômenos que vem-se tornando cada vez mais marcante na produção televisiva das últimas décadas é sua crescente vocação para falar muito mais de si própria do que dos acontecimentos do mundo exterior a que se propõe a relatar.

Segundo Baudrillard, o problema reside no fato de que os meios de comunicação remetem uns aos outros e só falam entre eles. O multimédium tornou-se intermédium. Essa situação se agrava quando a televisão curva-se inteiramente sobre si mesma. 
"Esse telecentrismo se desdobra num juízo moral e político implícito implacável: subentende que as massas não têm essencialmente necessidades nem desejo de sentido ou de informação - querem apenas signos e imagens; o que a televisão lhes fornece em profusão." (Baudrillard, 1997, p.159).

Em artigo por demais conhecido, TV: a transparência perdida, Eco afirmava, já em 1983, que uma das particularidades da televisão dos anos 80 era sua tendência a voltar-se para si própria mais do que para o real de que ela pretendia dar conta.

"La caractéristique principale de la neo-TV c'est le fait qu'elle parle de moins en moins du monde exterieur. Elle parle d'elle même et du contact qu'elle est en train d'établir avec son public" (Eco, 1998, p.198).

Embora esse narcisismo televisual tenha sido assinalado por Eco como um dos traços distintivos da neo-televisão, essa estratégia tem estado presente desde o início da televisão e, hoje, quando todos apontam para uma pós-televisão, ela permanece em franca ascensão, pois, se essa tendência não é nova, contemporaneamente esse fenômeno vem-se difundindo de forma vertiginosa, expressando-se sob diferentes e criativas modalidades e figuras de expressão e desempenhando funções estratégicas diversas. Daí por que cabe refletir sobre essas diferentes formas de autoconvocação de que a tevê lança mão - algumas sutis e subterrâneas, outras, escrachadas e ostensivas na sua reflexividade. Por que e como a televisão fala dela própria? Em que consiste esse discurso auto-reflexivo que ela faz sobre si mesma? De que formas ele se manifesta na produção televisiva? Limita-se a determinados tipos de emissão ou dissemina-se no conjunto da programação?

\section{- Sobre algumas distinções conceptuais}

Considerando esse fenômeno tão presente na produção televisiva, os teóricos não costumam distinguir as estratégias de que a tevê se utiliza nesse falar de si mesma, que correspondem, acreditamos, a dois procedimentos empregados de forma isolada ou combinada: metadiscursividade e auto-reflexividade. 
Hjelmslev foi o primeiro (1975, p.121-30) a aludir à presença de semióticas cujo plano de conteúdo é uma semiótica, aquelas podendo constituir-se como inteira ou parcialmente idênticas a essa última. Esse tipo de fenômeno discursivo, quando manifesto em nível inter e intratextual, é o que se costuma denominar de metadiscursividade. Assim, todo metadiscurso se funda em um procedimento de referenciação da ordem da recursividade; é recorrente, volta-se para um outro discurso, pré-existente a ele, do qual ele fala, constituindo-se esse em condição de sua existência e em sua razão de ser. Nessa perspectiva, todo metadiscurso atualiza relações intertextuais que se pautam por certas condições de precedência temporal.

Já a auto-reflexividade é um procedimento de auto-referenciação da ordem da incidência. Implica a presença de um sujeito que faça de si próprio objeto do discurso por ele mesmo produzido.

Tal como o entendemos, nem todo metadiscurso é auto-reflexivo, isto é, auto-referenciador. Ora, os textos televisivos aos quais aqui especificamente fazemos menção são aqueles que operam sobre outros, cujo conteúdo diz respeito aos processos comunicativo e produtivo da televisão ou mesmo aos seus próprios produtos. São programas, publicidades e outros textos, alguns marcadamente autoreflexivos: seu conteúdo se refere à própria história do meio televisão, ao tipo de processo comunicativo que a televisão instaura, às tecnologias de que se utiliza na produção, circulação e consumo de seus produtos, aos seus proprietários e dirigentes, aos atores e personagens de seus programas. Um programa como o Cena aberta, recentemente lançado pela RGT, sob o comando de Regina Casé, é um exemplo típico de auto-reflexividade que não implica metadiscursividade. Em Cena aberta não há distinção entre o que acontece por trás e frente às câmeras, entre dramaturgia e documentário. Nesse making of, ao telespectador é exibido todo o trabalho de produção: adaptação da história para a televisão, seleção do elenco, preparação dos atores, escolha das locações, ensaios. E a história é contada no decorrer dessas etapas de produção.

Outros programas têm um caráter essencialmente metadiscursivo: seu conteúdo fala de outros produtos. São publicidades, chamadas no interior da 
programação, ou mesmo programas cujo propósito é falar de outros programas, tais como o Videoshow ou o Caldeirão do Huck. Há ainda a combinação de metadiscursividade e auto-reflexividade. É só pensar no Globo Repórter apresentado em 10 de outubro de 2003. Sua temática eram as telenovelas, envolvendo história, cidade cenográfica, atores envolvidos e fragmentos das próprias novelas que foram sucessos de audiência da emissora. Assim, à metadiscursividade podem-se acrescer operações de auto-reflexividade (autoreferenciação) da televisão sobre ela própria. A combinatória de metadiscursividade e auto-reflexividade tem então como condição que o discurso sobre o qual se debruça o metadiscurso, tenha como conteúdo aspectos relativos à própria enunciação televisiva e, mais especificamente, aos sujeitos envolvidos nesse processo enunciativo.

Nessa direção, é necessário antes de tudo considerar que os produtos televisivos, como quaisquer outros textos, ao mesmo tempo em que representam ou constroem qualquer tipo de realidade discursiva a ser exibida, refletem a si próprios: sua mera enunciação altera o que é representado pelo fato mesmo de representá-lo. Nessa perspectiva, há sempre reflexividade da enunciação sobre o enunciado.

Por outro lado, a dimensão do falar de si própria depende não só dos aspectos manifestos nos próprios produtos, como também do próprio ponto de vista adotado por quem a examina. Assim, pode-se, por exemplo, examinar a manifestação desse fenômeno em relação à mídia televisão enquanto veiculadora de mensagens ou de certos efeitos de sentidos; aos dispositivos tecnológicos considerados como responsáveis pela estruturação do discurso televisivo; à estruturação dos próprios produtos enquanto reciclagens ou apropriações de outros produtos, e assim por diante.

Diante do exposto, tudo indica que a análise desses fenômenos, que aliam traços de recursividade e incidência, implica também a compreensão e interpretação de suas funções, bem como a identificação das formas de expressão empregadas na manifestação dessa metadiscursividade e auto-referenciação, ou 
seja, pressupõe examinar a conformação e funções desses fenômenos hoje tão presentes na televisão.

\section{- Sobre flashes da RGT}

À guisa de ilustração dos fenômenos mencionados, selecionaram-se alguns flashes com fragmentos da programação da Rede Globo de Televisão (RGT), no período compreendido entre 14/09 e 21/09/2003.

14/09/2003 - 18hoo: Domingão do Faustão. O apresentador aguarda, para iniciar um dos quadros do programa, a chegada das jovens atrizes Aline Moraes e Paula Picarelli, intérpretes do casal de lésbicas Clara e Rafaela, de Mulheres apaixonadas, que estavam participando de passeata em prol do desarmamento, para, juntamente com a atriz homenageada, Suzana Vieira, também personagem da referida novela, atuarem, como representantes femininas, na gincana musical, que se constitui em um dos quadros do programa.

14/09/2003 - 21hoo: Fantástico. Apresentação, no noticiário do programa, de reportagem sobre a passeata ocorrida no Rio de Janeiro em prol do desarmamento, com 40 mil pessoas, destacando imagens dos 40 atores da novela Mulheres apaixonadas que participaram do evento.

15/09 a 19/09/2003 - 9h: Sítio do Pica-pau Amarelo. Apresentação da terceira versão do seriado, inspirado no texto de Monteiro Lobato. Nos intervalos, chamadas para outros programas.

15/09 a 19/09/2003 - 14h15: Vale a pena ver de novo. Reapresentação da novela Anjo mau. Nos intervalos, chamadas para Mulheres apaixonadas.

15/09 a 20/09/2003 - 14ho0: Videoshow. Apresentação de concurso entre atores de Kubanacan.

15/09 a 20/09/2003 - 19h30: Kubanacan. Apresentação, todos os dias da semana, nos intervalos da novela, de chamadas com editoriais do Jornal Nacional, a ser exibido a seguir.

15/09 a 20/09/2003 - 20h30: Jornal Nacional. Apresentação, todos os dias da semana, nos intervalos do telejornal, de chamadas com exibição de cenas do capítulo de Mulheres apaixonadas, a ser exibido a seguir ao noticiário.

15/09/2003 - Apresentação em todos os telejornais da emissora - Bom-dia Brasil (7h15), Jornal Hoje (13h30), Jornal Nacional (20h30) e Jornal da Globo (23h30) das mesmas cenas já veiculadas pelo Fantástico, com imagens dos atores da novela participando da passeata em prol do desarmamento. 
15/09/2003 - 2oh3o: Mulheres apaixonadas. Exibição, no capítulo da novela, marcado pelo posicionamento francamente favorável ao desarmamento, de imagens de atores da novela, vestidos de branco, participando das cenas "reais" da passeata, no interior da ficção, com direito mesmo a hino nacional, tocado como pano de fundo.

16/09/2003 - 22hoo: Casseta \& Planeta urgente. Apresentação de quadros parodiando e satirizando cenas de Mulheres apaixonadas, no interior do programa Casseta \& Planeta, denominados Mulheres recauchutadas.

$>$ Violência na novela das oito faz com que atores passem a gravar de colete à prova de balas!!! - Plim-plim, Urgente!!! - Depois de mostrar alguém atingido por uma bala perdida, uma mulher que apanha de Salete e uma raquete que prevê o futuro, quer dizer... acho que não necessariamente nesta ordem, o autor de Mulheres recauchutadas promete que vem mais por aí... na semana que vem o Leblon será tomado por um terremoto e as duas lésbicas podem ser abduzidas por Teoni Ramos de outro planeta... É ver pra crer!!! Não acreditou o Plantão Casseta \& Planeta.

$>$ Sopapos acha que a violência no Leblon tem que ser resolvida na porrada!!! Quando o soco que é meu entrar no nariz que é seu, Urgente!!! - A violência no bairro da novela das oito está cada vez pior. Semana passada, por exemplo, um ator foi confundido com um porteiro e foi rendido por assaltantes que levaram metade do cenário. Outro dia, o operador de VT foi confundido com um flanelinha e levou porrada dos próprios atores. Um dos líderes foi o Sopapos, que enchulapou o pobre funcionário pensando que era a Carquel disfarçada...

$>$ Sócana diz que é religiosa e por isso bebe todo santo dia!!! Mais uma dose, Urgente!!! - E a corrupção chegou ao núcleo de Mulheres recauchutadas. Alguns alunos do colégio Ribeiro Alves, ao saberem que não passariam na matéria de Sócana, ofereceram uma "cervejinha" pra moça, que não se fez de rogada e aceitou na hora. Segundo os alunos, essa foi uma boa idéia para passar... e todo mundo sabe que boa idéia é com Sócana mesmo! Tomou uma 51 o Plantão Casseta \& Planeta.

$>$ Teoni Ramos acredita que este seja o papel mais cabeludo de toda a sua carreira!!! Pelo sim, pelo nãa, Urgente!!! - Resumo da novela: a menina Pivete descobre que o anjo de seus sonhos, nada mais é que um sujeito pendurado numa corda. A professora Carquel toma chá com porrada com o violento Sopapos. O cirurgião Sério Te Mello assume sua condição de homossexual e foge com o travesti do filme As panteras detonando. Sócana toma um porre, sobe numa árvore e grita que é "Billy Shears". Paulinha Sem-Alça descobre que Helena fez uma operação para mudar de sexo e que é seu pai verdadeiro. É mole ou quer mais?

16/09/2003 - 22h45: Carga pesada. Apresentação de episódio da nova versão da série.

18/09/2003 - 22hoo: A grande família. O episódio aborda como temática central as repercussões da novela Mulheres apaixonadas na vida familiar de Lineu, Nenê, Agostinho e Bebel. O ciúme de Bebel faz com que ela seja confundida com a Heloísa da novela das oito: todos acham que ela bateu no marido por estar enciumada. Por outro lado, o pacato Lineu, tentando ajudar o chefe Mendonça a se livrar da bebida, é tido como alcoólatra, exatamente como a personagem Santana. Flagrado pelo vizinho Goró, amigo de Agostinho, em uma reunião de apoio psicológico, espalha-se a fofoca, desconhecendo-se que Lineu só estava lá para dar força a Mendonça. Tuco é comparado com o personagem Cláudio, ao contar à família que está namorando uma garota virgem. E Roberta, uma antiga colega de 
escola de Nenê, pensando que ela e Marilda tivessem uma relação homossexual, convida as duas para uma festinha de iniciados em sua casa. Já Agostinho decide reunir seus amigos taxistas para protestar contra o personagem Caetano, que estaria denegrindo a sua imagem, causando a ciumeira de Bebel... É $A$ grande família em clima de novela das oito.

19/09/2003 - 24hoo: Programa do Jô. Entre os entrevistados está o ator Mário Gomes, participante da novela Kubanacan, que fala de seu personagem na novela e do disco que está lançando.

20/09/2003 - 22hoo: Zorra total. Reedições de quadros que permanecem em cena há mais de 30 anos.

21/09/2003 - 21hoo: Fantástico. Apresentação de quadro que festeja os trinta anos do Fantástico no ar, recuperando fragmentos de sua história, com ênfase nos apresentadores do programa. O texto verbal, acompanhado de imagens "históricas", dizia aproximadamente o seguinte:

\section{3 - O Fantástico estréia com uma receita original}

"Olhe bem, preste atenção". Assim uma voz feminina anunciava o Fantástico em 05 de agosto de 73. Misturar jornalismo e entretenimento de maneira dinâmica e acessível poderia ser uma idéia delirante, mas era a proposta inédita da revista eletrônica semanal que estreou sob a direção-geral de Augusto César Vanucci.

A equipe do programa costurava em preto e branco musicais, notícias internacionais, humor, teleteatro, números de variedade e noticiário diário. Desde o primeiro domingo, Cid Moreira já estava na bancada. Na estréia, emoção, entretenimento e informação garantidos.

Uma entrevista exclusiva com o ex-jogador Tostão mostrou o momento em que recebia o laudo médico que o fez parar de jogar. A atriz Sandra Bréa recordou Marilyn Monroe em uma performance. O humor ficou por conta de Chico Anysio e Raul Solnado. Falou-se até sobre o congelamento de portadores de doenças incuráveis para reanimação posterior.

\section{4 - A tecnologia muda o tom}

As "emoções que agitam o mundo" ganharam cor. Foi em abril de 74. E lá estava Cid Moreira - em cores e alguns anos mais jovem.

\section{7 - O jornalismo assume o comando}

Com José-Itamar de Freitas na direção-geral, a linha de espetáculos parou de conduzir tais fatos jornalísticos. Mesmo com a mudança de enfoque, não só o noticiário da semana aparecia nas noites de domingo.

Riso, drama, sexo, misticismo, guerra, amor, ciências... Tudo podia ser Fantástico se estivesse baseado na informação. Só havia uma proibição: usar uma linguagem difícil nas reportagens científicas.

\section{8 - A emoção ao vivo}

Em setembro de 88, o Fantástico passou a ser apresentado ao vivo por William Bonner, Sérgio Chapellin e Valéria Monteiro. Ainda sob a direção de José-Itamar de Freitas, abandonou um pouco seu lado revista para ser um jornal mais voltado para a atualidade. Mudança radical? Nem tanto. 
Música e humor continuaram a ser parte do programa. A cobertura jornalística crescia, com equipes de reportagem em várias regiões do país e escritórios na Europa e nos Estados Unidos. E pensar que, no primeiro ano de Fantástico, apenas Hélio Costa e o cinegrafista Henrique Oliver mandavam matérias dos Estados Unidos...

\section{5 - A inovação é também do cenário}

No aniversário de trinta anos da Rede Globo, o Fantástico ganhou agilidade. Com Luiz Nascimento na direção-geral, a bancada dos apresentadores foi abolida. Fátima Bernardes, Celso Freitas e Sandra Annenberg passaram a apresentar matérias transitando por placas e módulos com o logotipo do programa.

E essa desenvoltura permanece até hoje, com o cenário virtual que deixa Zeca Camargo, Pedro Bial e Glória Maria à vontade para apresentar notícias.

\section{2 - O sucesso continua Fantástico}

O Fantástico é um sucesso porque não tem fórmulas rígidas, ou não tem fórmulas rígidas porque é um sucesso?

Comandado pelo jornalismo, o programa muda de acordo com as circunstâncias. De musical-verdade a show ao vivo, de Marília Pêra a Denise Fraga, da gestação humana ao tempo dos dinossauros, do trapezista Peter a David Copperfield, de Chico Anysio ao Casseta \& Planeta, quadros e séries são criados de acordo com as necessidades dos temas abordados. "Da idade da pedra ao homem de plástico", o Fantástico sempre foi mescla de verdade e fantasia, pesquisa e imaginação. Nasceu como uma linguagem experimental e, hoje, é retrato de uma televisão madura e responsável.

\section{- Sobre as modalidades, configurações e funções}

As modalidades e configurações de expressão e as funções desempenhadas por essas estratégias - metadiscursividade e auto-reflexividade - vêm variando no decorrer da história da televisão. Em primeiro lugar, pode-se reconhecer que ambas as estratégias empregam duas modalidades de expressão: (1) a explícita e ostensiva; (2) a implícita e sutil. Na primeira modalidade, enquadram-se todos aqueles produtos que assumem o seu caráter promocional e publicitário, tais como as chamadas de lançamento de produtos, com suas promessas referentes às características ofertadas; as chamadas que alertam para a seqüência da programação, visibilizando diariamente fragmentos dos episódios de seriados e serializações, que se sucedem; ou ainda aquelas chamadas que apelam diretamente o público à participação em programas. Também dessa modalidade fazem parte as referências explícitas, no interior de outros programas - telejornais e magazines -, a índices de audiência, ou à aquisição de tecnologia (Vide Faustão de 5/10/03). Há ainda os programas humorísticos que operam com diferentes níveis de paródias. Como se pode ver, 
essa primeira modalidade comporta exemplos de auto-reflexividade (índices de audiência); de metadiscursividade (programas humorísticos); e de metadiscursividade auto-reflexiva (chamadas).

Valeria também destacar que os agenciamentos discursivos, próprios dessas figuras, apresentam-se sob dimensões variáveis: às vezes, constituem-se nos próprios produtos como um todo, de chamadas promocionais aos próprios programas; outras, em meros fragmentos de produtos.

Mas, como já se ressaltou, a par de uma modalidade ostensiva de expressão desse fenômeno, a televisão desenvolveu formas mais sofisticadas e sub-reptícias. Quanto a essa segunda modalidade, é preciso que se diga, suas configurações assumem diferentes graus de sutileza, como se pode ver pelos próprios flashes anteriormente apresentados, envolvendo estruturas dissipativas - tais como citações que atravessam a programação e cujo valor não é só promocional, mas também aponta para a maneira como as emissoras concebem sua própria identidade. Talvez um dos graus mais baixos de sutileza seja representado pela figura do convite a si própria, representado pela inserção de atores, apresentadores, âncoras, diretores, escritores, roteiristas ou repórteres da emissora no interior de programas, que fazem deles os acontecimentos que alimentam a própria programação, num balé alucinante, em que as mesmas cabeças se cruzam e retornam sem nunca sair da tela. Assim, se há os talk shows que fazem os atores da emissora estarem sempre na tela, muitas vezes, o fenômeno se manifesta pela mera citação de fragmentos de imagens ou expressões verbais no interior de programas. Essa forma difusa de emprego dessas figuras passa por inserções no interior da programação, pela transformação de atores televisivos, de sua vida e feitos, em conteúdo de outros programas, etc.

Não obstante - e essa possivelmente seja a mais importante função estratégica desse fenômeno -, é no entrelaçamento dessas vozes que as emissoras se constroem como enunciadores discursivos, pois é a partir do emprego dessas estratégias de metadiscursividade e auto-reflexividade que emerge um sujeito tevê: só ele é suscetível de produzir um discurso sobre si próprio. As emissoras procuram 
constituírem-se como personalidades do mundo - atores sociais -, sustentando sua personalidade na co-existência dessas diferentes modalidades discursivas. E só um sujeito que pode transformar a si próprio em objeto de seu discurso pode interpelar outros sujeitos.

Naturalmente, em televisão, o espaço de publicização desses discursos é a própria programação: assim, as emissoras falam de si através de sua programação e de seus produtos. O exame dessas estratégias de metadiscursividade e autoreflexividade permitem identificar a recorrência a diferentes tipos de vozes, muitas vezes co-presentes:

- as da empresa, estabelecendo suas ligações com a realidade sócioeconômica e jurídica;

- as da instituição, apresentando seus pontos de vista acerca do espaço público e dos papéis e funções que se auto-atribui enquanto missão a cumprir: fundação ou participação em acontecimentos;

- as do marketing, referindo-se à promoção de produtos, ou à competência e qualidade da emissora;

- as de interação com o telespectador, interpelando-o a diferentes formas de participação;

- as de constituição de um real paralelo, que se constitui no interior do próprio meio e passa a alimentar referencialmente suas realidades discursivas.

Dentre as configurações expressivas mais empregadas na constituição desses diferentes discursos, às vezes superpostos, estão:

\section{(a) a produção de programas cujo tema são outros produtos da emissora.}

Existe uma série de programas, em cada emissora, cuja temática e propósito central é dizer de outros produtos da emissora. Veja-se o caso da RGT, que abusa dessa estratégia. Há o Videoshow, o Caldeirão do Huck, e o próprio Casseta \& Planeta, que desempenham essa tarefa sistematicamente, acompanhados pela mídia expandida, representada pelos outros meios de comunicação - outros canais de televisão, aberta ou fechada, jornais, revistas, sites, etc., da mesma rede. 
Há ainda outros programas que lançam mão dessa estratégia de forma mais eventual. Um bom exemplo disso foi o que aconteceu no A grande família e Globo repórter citados nos flashes.

(b) a reapresentação, os remakes, as novas versões de programas inteiros ou de fragmentos ou quadros.

Uma outra vertente dessas estratégias é a recuperação e reapresentação ou mesmo os remakes de programas antigos. Pense-se em Carga pesada, Vale a pena ver de novo, A grande família, Zorra total. As constantes citações utilizadas em televisão interpelam constantemente o conhecimento de telespectadores habituados à televisão, e, portanto, aptos a dotar de sentido as referências feitas.

(c) a utilização de programas humorísticos como paródias de produtos televisivos.

A culminância da citação é a paródia, hoje usada como recurso fundamental do humorismo televisivo. No outro extremo do arco está a cópia, que funciona como estratégia das emissoras invejosas do sucesso dos programas concorrentes. É o que faz Casseta \& Planeta ao colocar em cena, sob a forma de paródia, figuras, atores e narrativas fundadas em outras - novelas, minissériess - produzidas pela própria emissora em destaque e apresentação no momento.

Com a paródia e a citação, a televisão recicla a si mesma, fazendo de seu próprio discurso o único horizonte discursivo, inclusive quando opera com atores ou sentidos que não tiveram origem nesse meio.

(d) a apresentação permanente de seus atores; sua circulação em outros programas da emissora e mesmo na mídia expandida.

Inúmeros são os exemplos de emprego dessa figura de expressão. À guisa de ilustração cita-se a construção feita em torno dos dois apresentadores atuais do Jornal Nacional, William Bonner e Fátima Bernardes, cujo casamento, gestação e nascimento de seus trigêmeos foram amplamente divulgados pela emissora. Embora o casal assuma uma postura discreta, tentando evitar a exposição de sua 
vida privada pela mídia, eles estão permanentemente na mira das câmeras. As dificuldades de engravidar de Fátima foram exploradas por diversos programas, tais como Fantástico e Globo Repórter; a gravidez da apresentadora foi anunciada no Jornal Nacional, bem como o seu afastamento para o nascimento dos trigêmeos e posterior retorno. Quando o casal goza férias, o fato é comunicado aos telespectadores. A relação discursiva estabelecida com o público telespectador é tão intensa que até mesmo quando Fátima Bernardes muda de visual, é obrigada a comparecer a alguns programas televisivos para explicar as alterações. O alisamento dos cabelos, no início de 2003, com uma técnica chamada alisamento japonês, transformou-se em notícia, sendo a técnica empregada explicada em detalhes no ar, com indicação de preços e locais recomendados para a execução do trabalho. A apresentadora prestou depoimentos revelando sua satisfação com o novo visual em pelo menos três programas: Videoshow, Fantástico e Domingão do Faustão. Além disso, a notícia transformou-se em tema utilizado por outros programas da emissora, como o Mais Você, havendo repercutido, também, em outras mídias.

(e) a visibilização dos bastidores, a referência a momentos anteriores à transmissão, ou ao que está por detrás das câmeras.

A apresentação do processo de produção - a visibilização do em-se-fazendo dos programas, do a si própria ao vivo, de câmeras, microfones, computadores, equipe em funcionamento, tropeços, etc. Esta figura pode ser vista em programas mais sérios, como o Jornal Nacional, ou mais descontraídos, como Sai de baixo ou Muvuca.

Assim, a televisão se apresenta a si própria ao vivo, mesmo nos casos de transmissões gravadas e editadas - pense-se aqui em exemplos como os já referidos, tais como Sai de baixo -, e não pretende mais apagar os sinais do ao vivo. Tais sinais se tornaram tão típicos de sua estética que persistem mesmo nos programas gravados e editados: todos os programas humorísticos são autoreflexivos; os telejornais estão cheios de comentários auto-reflexivos sobre a tarefa realizada para conseguir as imagens da notícia; os programas jornalísticos mais 
sérios incluem avaliações da audiência deles próprios, que se olham a si mesmos no espelho das escolhas do público; os apresentadores não hesitam em mencionar suas dificuldades, os tropeços organizativos, ou os fatos que estão acontecendo por trás das câmeras; os artistas convidados e os apresentadores de shows de variedades sempre fazem menção aos momentos anteriores à transmissão, revelando as condições de produção do que se verá depois; os proprietários de emissoras podem irromper em tomadas e exibem a verdade de seu poder no vídeo. As câmeras deslocam-se pelos estúdios, captando ângulos diferentes; refletores e microfones aparecem nos enquadramentos. Enfim, toda a mise-en-scène é produzida de forma a gerar efeitos de improvisação, associados a traços de legitimidade e autenticidade dos quais se beneficia a tevê, que então se apresenta não apenas como produto, mas como processo de produção.

O ensaio realizado pela RGT em Cena aberta, comandado por Regina Casé, tinha como proposta acabar com a distância entre o que acontece por trás e em frente às câmeras, esboroando as fronteiras entre a dramaturgia e o documentário.

Segundo a própria emissora, a idéia era oferecer uma boa história de ficção, mostrando ao mesmo tempo o seu trabalho de produção. A trama no programa era revelada enquanto o telespectador acompanhava o processo de adaptação da história à tevê, a seleção do elenco, a preparação dos atores, a escolha das locações, os ensaios, a caracterização dos personagens, os truques de filmagem, dublagens, etc.

Desde o primeiro episódio, A hora da estrela, uma adaptação do livro de Clarice Lispector, percebe-se a tentativa de integração de artistas famosos a pessoas anônimas, de lugares onde foram feitas as locações a cenários, articulando planos diferentes de realidade. Trata-se de um reality show cujo tema é o próprio processo de produção televisivo.

(f) a apresentação de fragmentos contendo hinos à modernidade tecnológica da emissora. 
Essa configuração costuma aparecer no interior de programas, geralmente como anúncios explícitos, feitos até mesmo em telejornais.

\section{(g) a visibilização do contrato e das relações propostas ao telespectador, sua convocação à participação, a explicitação das tarefas que lhe são concernentes.}

Essa configuração aparece comumente nas chamadas promocionais de programas, contendo as promessas atrativas da emissão a ser exibida.

(h) a superposição, o imbricamento entre planos diferentes das realidades com que opera: meta-realidade, supra-realidade, pararealidade.

Se a operação com essas duas estratégias discursivas - metadiscursividade e auto-reflexividade - parece desempenhar simultaneamente uma diversidade de funções na comunicação televisiva, algumas delas são evidentes, referindo-se à construção da imagem da própria instância enunciadora, à apresentação da identidade da emissora, ao estabelecimento de relações de proximidade e familiaridade com o público, enfim à promoção dos produtos que uma emissora oferta ao mercado. Mas, para além dessas funções mais evidentes, hoje a televisão utiliza-se dessas estratégias em suas diferentes modalidades também tendo em vista uma outra função: aquela relativa à constituição de um real paralelo que serve de referência às realidades discursivas com que vem operando. No interior desse real paralelo, os acontecimentos artificialmente produzidos são provocados e controlados pela própria mídia, muitas vezes através desses procedimentos.

Na seqüência, fundada nessas estratégias de metadiscursividade e autoreflexividade, transforma essa para-realidade apresentada por esses tipos de programas em tema de outros produtos de sua programação - telejornais, variedades, humor, e mesmo novelas. Ocorre que, ao operar com esses diferentes níveis de realidade - o referencial, o ficcional e o artificial -, a televisão embaralhaos, às vezes no interior de um mesmo programa. É a televisão dos reais recorrendo a meios ficcionalizantes; é a televisão de ficção perseguindo operações realizantes. 
O uso feito do personagem Seu Creysson (Casseta \& Planeta) ilustra bem essa figura. Interpretado pelo ator Cláudio Manoel, o personagem, acompanhado da única mulher do Casseta \& Planeta Urgente!, Maria Paula arrastou uma multidão para o seu showmício na Praça da República, no centro de São Paulo, na campanha eleitoral de 2002.

Durante o evento, foram distribuídos 60 faixas, 250 camisetas, 70 placas, 200 bandeirinhas e 200 bottons. Para terminar, Seu Creysson participou de uma carreata ao redor da praça, seguido por carros e uma multidão de fãs que parecia não se importar por estar no meio da muvuca. O showmício foi ao ar no Casseta \& Planeta da terça-feira seguinte, e o candidato foi entrevistado na bancada pelos apresentadores do Jornal Nacional.

Ora, essa constante e indiscriminada mistura de informação e entretenimento, esse embaralhamento entre a novela e o telejornal, entre o real natural e o paralelo artificial, entre atores sociais e discursivos pode ser muito atrativa para a própria emissora, que passa a gerar os acontecimentos que noticia e conseqüentemente detém o controle sobre eles. Mas, e a confusão causada na cabeça dos telespectadores?

\section{- À guisa de conclusão}

Não há dúvida de que a familiaridade da televisão com o telespectador e a proximidade imaginária que o público estabelece com a televisão é sustentada, de certa forma, por essas estratégias de metadiscursividade e auto-reflexividade.

Nem todos estão cientes de que a televisão só exibe os bastidores quando estrategicamente propõe essas visitas guiadas pelas câmeras com uma função: a de aproximação e de interiorização de seu público: há determinados laços de cumplicidade e afetividade que só se estabelecem quando se permite ao outro que adentre nossa cozinha.

Talvez por isso, o recurso improvisado de alguns atores e apresentadores, em uma época em que a maioria se esforçava para ocultar as marcas do que estava 
sendo feito e apresentava os produtos como coisa feita, hoje tenha se transformado em uma figura de estilo de produtividade indiscutível da gramática televisiva; essas estratégias empregadas para falar de si própria - metadiscursividade e autoreflexividade - com que opera a televisão, tornam possível o jogo de cumplicidades entre a televisão e o público telespectador.

Mas, apesar da criatividade revelada por tais artimanhas, não nos enganemos: a televisão se mostra e, ao mostrar-se, é sincera - está de mãos limpas. E é essa recorrência a um realismo, essa alusão constante à maneira como a vida chega até ali, que desloca e relega para um segundo plano as providências discursivas tomadas para que a vida seja atraente e não simplesmente sórdida ou banal.

Dessa forma, como se vem já apontando no decorrer dessa reflexão, com o desenvolvimento dessa produção televisiva voltada à apresentação do real, da verdade, surge uma nova modalidade de auto-reflexividade: aquela responsável pela constituição de um real artificial no interior do próprio meio.

A convergência entre televisão, câmeras de vigilância e internet vem sustentando a constituição dessa nova modalidade de discurso - a para-realidade que de certa forma libera a televisão da tirania do mundo natural, ao mesmo tempo em que oferta uma relação de dominância e de poder aos telespectadores, fundada no olhar e no vigiar. Evidentemente essa relação de dominância é enganadora, pois a televisão seleciona previamente o que dá a ver.

Ao exibir as lógicas - econômica, tecnológica, institucional - que presidem a produção de seus produtos e estruturam seu discurso, ao desvelar seus próprios dispositivos de realização, seus bastidores, a tevê se traduz enquanto omnipresença, mas não fornece indicações sobre um possível e necessário retorno crítico da televisão sobre ela própria. 


\section{Bibliografia}

1. BAUDRILLARD, Jean. Tela total: mito-ironias da era do virtual e da imagem. Porto Alegre: Sulina, 1997.

2. BEYLOT, Pierre. Quand la télévision parle d'elle même. Paris: L'Harmattan, 2000.

3. BOURDON, Jérôme \& JOST, François, orgs. Penser la télévision: actes du colloque de Cerisy. Paris: Nathan, 1998.

4. CALABRESE, Omar. A idade neobarroca. Lisboa: Edições 70, 1987.

5. CHAMPS Visuels. Revue interdisciplinaire de recherches sur l'image. n.8. fev.1998. Paris: L'Harmattan.

6. DICIONÁRIO da TV Globo. v.1: Dramaturgia \& Entretenimento. Rio de Janeiro: Zahar, 2003.

7. ECO, Umberto. La guerre du faux. Paris: Grasset, 1985.

8. FABBRI, Paolo. El giro semiótico: las concepciones del signo a lo largo de su historia. Barcelona: Gedisa, 1999.

9. GARDIES, René \& TARANGER, Marie-Claude, orgs. Télévision: questions de formes. Paris: L'Harmattan, 2001.

10. HJELMSLEV, Louis. Prolegômenos a uma teoria da linguagem. São Paulo: Perspectiva, 1975.

11. JOST, François. La télévision du quotidien: entre réalité et fiction. Bruxelles: De Boeck Université, 2001.

12. LOCHARD, Guy \& BOYER, Henri. Notre ecran quotidien: une radiographie du télévisuel. Paris: L'Harmattan, 2002.

13. MACHADO, Arlindo. A televisão levada a sério. São Paulo: SENAC, 2000.

SARLO, Beatriz. Cenas da vida pós-moderna: intelectuais, arte e vídeo-cultura na Argentina. Rio de Janeiro: UFRJ, 1997.

i - Professora Dra . Elizabeth Bastos Duarte. Unisinos. Av. Unisinos, 950 - São Leopoldo, RS. CEP: 93022-000. bebeth@unisinos.icaro.br. Fones: (51) 590 - 3333 R: 1357. 